\title{
THE THEORY OF GRINDING,
}

\section{WITH REFERENCE TO THE SELECTION OF SPEEDS}

\section{IN PLAIN AND INTERNAL WORK.}

By JAMES J. GUEST, of Birmingham.

Introduction.-When the Author is asked to advise upon plant installation, the grinding machines proposed are those upon which most discussion arises, and of the points connected with grinding, that of work-speed selection is the least understood. The question which he is most frequently asked is "What is the best workspeed?" The inquirer often volunteers the information that he does not mean revolutions per minute, but the actual surface-speed of the work, which he considers should be some certain fixed amount, at any rate for a given material, such as mild steel. The question is often answered by a direct statement that the speed should be so many feet per minute, but unfortunately for the questioner, each time he asks the question he receives a different reply.

The speeds now recommended vary from 6 to 80 feet per minute; some authorities advise a range from 35 to 70 feet per minute; while others pin their faith to one definite amount-for example, 25 feet per minute. The surface speeds formerly in use were much higher-from 120 to 400 feet per minute-and a belief

[The I.Mech.E.] 
in the value of high speeds still exists; so much so indeed that one voluminous writer states it to be a self-evident proposition that the higher the work-speed, the greater the output.

Having received his answer, or looked up the various opinions, the anxious inquirer naturally wishes to know whether the same speed should be used on internal work. Here he finds that there is much more reticence. As improvement takes place in any manufacturing process, it is natural that the speeds advisable should be subjected to change; but in this case the change of practice which has slowly taken place is very great, and is in the unusual direction of lowering speeds.

This universally accepted idea of a standard work surface-speed --independent of the diameters of the work and of the wheel, and of the particular machine used-the author regards as based upon an illusion, probably arising from the similarity of the shape of the work produced by a Universal grinder and a lathe, and a knowledge that there is a (more or less precise) correct work surface-speed in the latter case. The analogy between the actions in a plain grinder and a lathe is false; a better one would be with a circular milling-machine, the cutter-speed in which corresponds to the wheel-speed in grinding.

Some years ago the Author developed the theory of grinding, which he has found of much service, and he presents it here for consideration unbiased by preconceived ideas. The basis of it is given in his Paper before the British Association for the Advancement of Science in 1914, and it is further discussed in his book on "Grinding Machines." It is there treated somewhat discursively, but he will endeavour in this Paper to cut all side issues short, and to present the argument in such a logical form as appeals to engineers.

Limit of Wheel-Speed.-In order to make matters definite and clear, take the case of a piece of work of diameter $d$, running with surface velocity $v$, being ground by a wheel of diameter $\mathrm{D}$, with a depth of cut $t$ on the work diameter, and with traverse $c$ per revolution of the work. Also confine the attention initially to 
wheels of one fixed grit and grade, and to work of one particular material.

First, consider the effect of time and determine what it is that prevents the speeds, and so the output, from being increased indefinitely. In the case of a lathe or milling-machine, if an attempt be made to increase the speeds continuously, the effect of the heat produced soon enforces a limit, but this does not apply directly to grinding, as the abrasive particles (whether corundum, alundum, or carborundum), whose points do the cutting and make the chips, will withstand a very high temperature without injury. The word directly is used because the rate of production of heat does produce secondary effects, which formerly frequently controlled the production and even now occasionally do so, although a large flow of water is used. This, however, is a matter aside from the immediate inquiry, and as such is dismissed from the discussion. Similarly, other side issues-for example, the control of the wheelspeed by the material, and ultimately by the abrasive, of the wheel, which arises in the succeeding paragraph-will not be pursued.

In grinding, the speed limit is controlled by the strength of the material of the wheel. The rotation of a wheel causes stresses in its material, proportional to the square of its velocity, and it can easily be shown * that the stress in a wheel depends only upon the speed of its edge $V$, and not upon its diameter. The decision that a certain factor of safety is necessary limits the highest speed of the wheel-edge to a definite amount. The speed permissible actually varies with the grade of the wheel, but this is foreign to the present issue, and the maximum velocity of the wheel-edge is taken to be $\mathrm{V}$, and to be determined by considerations of safety.

The interaction of wheel and work surfaces may be looked upon from two distinct points of view-the geometrical and the mechanical. If the surfaces go through certain interactions, viewed from the geometrical standpoint, in time $t$, the effect of taking time $2 t$ over the same movements is to lessen the rate of doing the work (and of producing heat) in the same ratio. There may be a minute

* Proceedings, Institution Automobile Engineers, 1911-12, vol. vi, page 331. 
difference in the power required, heat produced, etc., due to a small difference in the shape of the stress-strain curve. This variation of the rate of heat production will not, with a good water-supply, disturb matters, and therefore if any lower velocity than $\mathrm{V}$ be used, and $v$ lowered in the same ratio, the same action will take place, merely more slowly, and with a corresponding diminution in the rate of output. Hence the wheel is to be used at the highest safe surface-velocity, $\nabla$, for reasons of production.

Normal Material Velocity alone Effective.-If, instead of having a depth of cut $\frac{1}{2} t$, the wheel only just grazes the work surface,

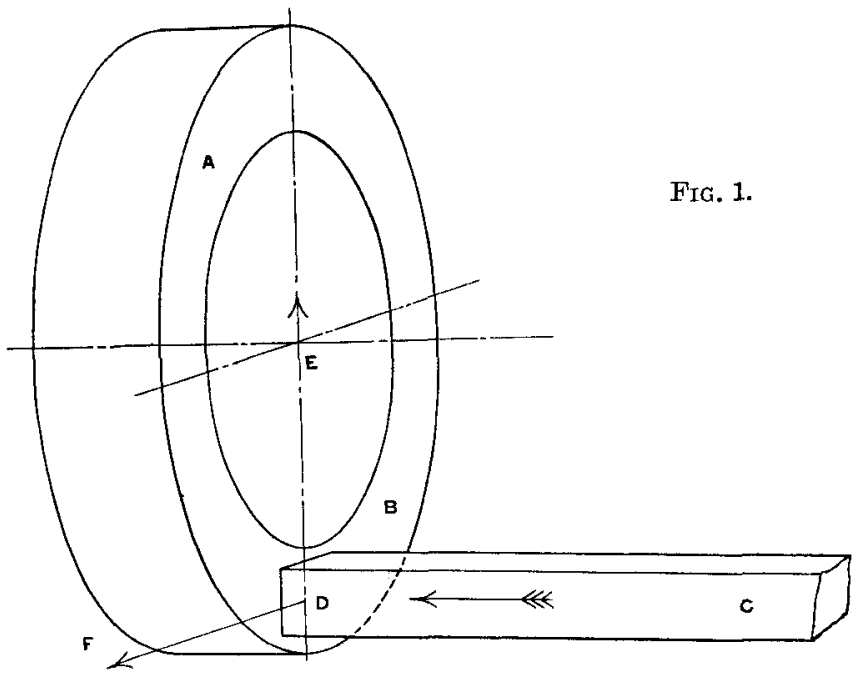

neither the rotation nor traverse of the work, singly or combined, will result in any material being ground off. Here the work surface moves by the wheel surface in lines the same as that of the velocity of the wheel particles and perpendicular to this direction (V) respectively. So that, considering a very small portion of the work surface just as it grazes the wheel surface, it becomes clear that no velocity which it has in its own plane can have any effect 
on the actual grinding or on the amount of material removed. Such a velocity merely presents quantity of work surface to the wheel.

In grinding, therefore, the third component of the work at the wheel-face must be the effective one, and, geometrically considered, it must be the fundamental controlling factor. The Author calls this quantity the normal material velocity, as it is the component of the work velocity which is normal to the wheel surface. To illustrate this, suppose that a cup-wheel with a flat face AB, Fig. 1, be rotating, and a bar of steel CD be held with its end against the wheel-face, so that the length $C D$ is perpendicular to the face $A B$. If the bar is pushed lengthwise directly into the wheel, it will receive this normal material velocity only, and will be ground away. If it be moved sideways only, whether parallel to $\mathrm{DE}$ or $\mathrm{DF}$, no material will be ground away. If the bar received the three movements simultaneously, the amount ground away would depend on the normal velocity only. If the bar were pushed rapidly into the wheel-face, it would disintegrate it and cause the wheel to waste away. If it be fed in very slowly indeed, the particles of the wheel will gradually become dull and then polished; the wheel-face will then be "glazed" and it will be difficult to force the bar in. These two effects limit the possible amounts of the normal material velocity; between them lies the region of grinding within which there is some value of this velocity (depending chiefly upon labour and wheel costs), which may be regarded as the best.

Value of the Normal Material Velocity.-In the case of circular grinding, which is under consideration, where an amount $t$ is being removed from the diameter, the work must have some normal material velocity into the wheel at the arc of contact, although this are is so short. It is now necessary to find the value of the normal material velocity in this case of plain (or external) grinding. In Fig. 2 (page 548) the contact of the wheel and work is shown on a distorted scale for the sake of clearness-the depth of cut having been made very excessive. Here $A$ is the centre of the wheel BCE, and $F$ the axis of the work GHEJ ; while KCL represents the continuation of the work surface $\mathrm{JE}$ as it would have been if not ground away, 
so that HK is the depth of cut or $\frac{1}{2} t$. The wheel is rotating in the direction marked by the arrow $\mathrm{V}$ and the work in the same direction, marked by the arrow $v$. The part of the work GHEKCL is ground away, so that the are of contact is $\mathrm{HE}$. If the number of cutting points on the wheel-face be estimated and the size of the chip deduced, it will be found that the arc of contact extends a little above $\mathrm{H}$ towards $\mathrm{C}$, but that this distance is so small compared with HE that it need not be considered. Join AE and draw FM perpendicular to it (produced). Produce AKHF to cut the

FIG. 2.

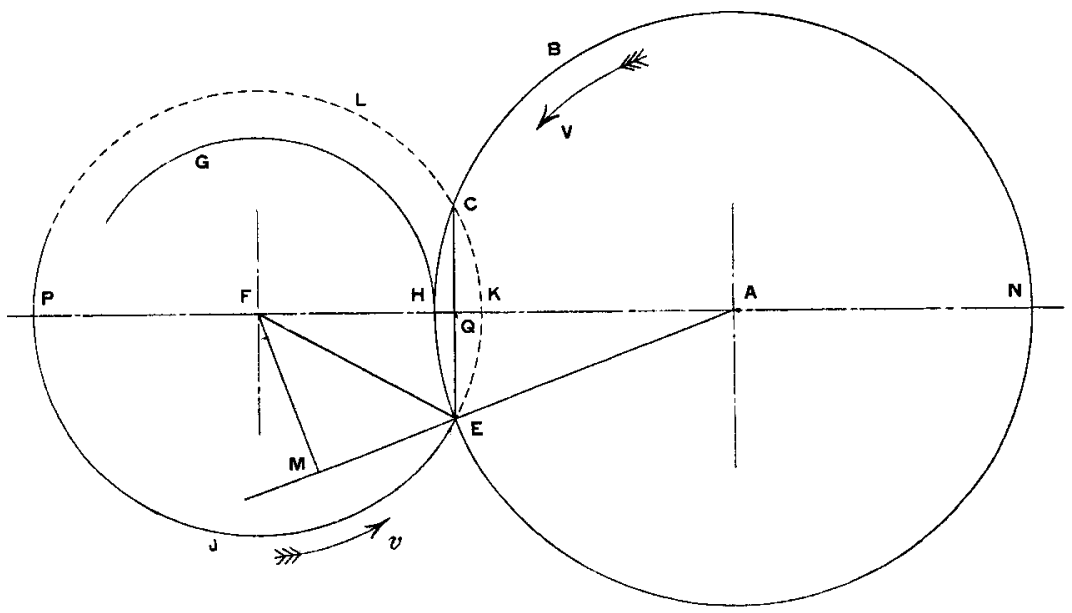

wheel and work circles in $\mathrm{N}$ and $\mathrm{P}$ respectively, and join $\mathrm{CE}$ cutting this line in Q, and join FE. Now (by Euclid iii. 35) the product of chords in a circle are equal, and

$$
\begin{aligned}
\therefore \mathrm{HQ} \times \mathrm{QN} & =\mathrm{QE}^{2} \\
\therefore \mathrm{HQ} & =\frac{\mathrm{QE}^{2}}{\mathrm{QN}},
\end{aligned}
$$

similarly

$$
\mathrm{KQ}=\frac{\mathrm{QE}^{2}}{\mathrm{QP}}
$$

and

$$
\therefore H K=H Q+K Q=Q^{2}\left(\frac{1}{Q N}+\frac{1}{Q P}\right) \text {. }
$$


Now HK is the depth of the cut or $\frac{1}{2} t$, and in practice is of the order of 0.001 inch, so that, similarly to its parts $\mathrm{QH}$ and QK, it is small compared with the diameters of the wheel and of the work. Hence QN may be taken as equal to $\mathrm{HN}$ or $\mathrm{D}$, and $\mathrm{QP}$ as equal to KP or $d$ in the above equation. Also, since the base $\mathrm{HQ}$ of the curved triangle HEQ is so small, QE may be considered as equal to $\mathrm{HE}$ or 8 .

Substituting these values in the above equation, it becomes

$$
\frac{1}{2} t=s^{2}\left(\frac{1}{\mathrm{D}}+\frac{1}{d}\right)
$$

so that the length of the arc of contact is

$$
s=\sqrt{\overline{2(\bar{d} \bar{d}+\mathrm{D})}}
$$

Now at $\mathrm{E}$ the particles of the work are moving with velocity $v$ perpendicular to $\mathrm{FE}$, and this velocity will have components $v_{1}$ (the normal velocity of the material) along EA and $v_{2}$ along the wheelface $\mathrm{EH}$, perpendicular to $\mathrm{EA}$. These directions are perpendicular respectively to the sides $\mathrm{FE}, \mathrm{FM}$ and $\mathrm{ME}$ of the triangle FME, so that it is a triangle of velocities, and

$$
\therefore \quad v_{1}=\frac{F M}{F E} v .
$$

Now $\quad F M \times A E=2 \times$ Area of triangle FEA

$$
=\mathrm{EQ} \times \mathrm{FA}
$$

or

$$
\mathrm{FM}=\frac{\mathrm{EQ} \times \mathrm{FA}}{\mathrm{AE}} \text {. }
$$

But $\mathbf{F A}=\mathrm{AH}+\mathrm{FK}-\mathrm{HK}=\frac{1}{2}(\mathrm{D}+d-t)$, but as $t$ is so small compared with $\mathrm{D}+d$, it may be omitted, and the equation becomes

and

$$
\begin{aligned}
\mathbf{F M} & =s \frac{d+\mathrm{D}}{\mathrm{D}} \\
\therefore \quad v_{1}=\frac{\mathrm{FM}}{\mathrm{F} \mathrm{H}} \times v & =s \frac{d+\mathrm{D}}{\mathrm{D}} \times \frac{v}{\frac{d}{d} d}=2 s v \frac{d+\mathrm{D}}{d \mathrm{D}} \\
& =v \sqrt{2 t \frac{d+\mathrm{D}}{d \overline{\mathrm{D}}}} .
\end{aligned} .
$$


This, then, is the value of the normal material velocity at the point E, and will control the grinding at that point.

It cannot, however, be concluded immediately that it controls the grinding completely, as the normal velocity varies all along the arc from the value zero at $\mathrm{H}$ to the amount just found at $\mathrm{E}$. Equation (2) states that $v_{1}=2 v s \frac{d+\mathrm{D}}{d \mathrm{D}}$,

and, as in the proof of this, no specification as to the value of the depth of the cut has been made, this applies all along the arc HEthat is, any other point in HE may be supposed to correspond to the point $\mathbf{E}$ for a smaller depth of cut and very slightly less diameter of work. Since the quantities $v, d$ and $\mathrm{D}$ are the same within insignificantly small amounts, this shows that the value of $v_{1}$ at every point along the arc of contact is proportional to the length of the arc $s$ measured from $H$ to that point. Hence, whether the arc of contact in any case is long or short, provided that the final value of $v_{1}$ is the same, a cutting particle is subjected to the same normal material velocity at corresponding intermediate points; so that whether a cutting point, in its history of getting blunt, passes a large number of times over a short arc or a fewer number of times over a longer arc, it receives equal amounts of action under equal normal material velocities. Just the same applies to particles whose points lie a little lower in the wheel than those which at any moment are taking their full cut, so that the total result is that the history of all particles is similar, provided that the final normal velocity of the material at $E$ is the same. Hence the quantity $v \sqrt{\frac{2 t(d+D)}{d D}}$ is the controlling factor, and if it is too large the wheel will wear away unduly, while if it be too small the wheel will glaze. In the first part of the history of a cutting point the normal material velocity is very small and the action is a glazing one; in the latter part it is greater and the action finally fractures the particle or forces it from its bond in the wheel.

The force of the cut on any particle will depend on the normal material velocity, and it is the force which fractures or dislodges 
the particle of abrasive; beyond this the actual value of the force is not of present importance. The action gradually blunts the particle and so increases the width of the chip; this increases the force produced by the same normal velocity, so that a particle is not immediately fractured or dislodged by a certain normal velocity, but such an event occurs after a certain amount of action.

Let $\sqrt{ } 2 a_{1}$ be the value of $v_{1}$ at which glazing just takes place, and $\sqrt{2 a_{2}}$ that at which the wheel wears unduly. Some intermediate value $\sqrt{2 a}$ will be the best value, and for it the equation becomes

$$
\frac{d+\mathrm{D}}{d \mathrm{D}} \times t v^{2}=a
$$

This is the equation giving the best value of the work-surface velocity $v$, and it shows that it does not depend on the nature of the wheel and of the material ground only, but also upon the diameters of both work and wheel, and upon the depth of cut.

If $v$ be increased from this best value, the normal material velocity gradually rises until the value $\sqrt{2 a_{2}}$ is reached, at which the wheel wastes away too rapidly; its value is not a precise one, but is a matter of the balance of wheel and labour costs. When the quantities are so large that the grinding is done in two operations, a higher value of $v_{1}$ should be used in the rough grinding than would be satisfactory in cases when parts are finished at once. The best value of $a$ is therefore also somewhat higher in the former case.

Equation (4) shows that some function of $d, \mathrm{D}, v$ and $t$ is to be constant in order that the wheel should work well; but even in grinding one particular piece of work with one definite wheel (so that $d$ and $\mathrm{D}$ are given), the two quantities $v$ and $t$ may be varied, and yet the equation be satisfied perfectly.

The Material Removed.- The rate of removing material is $\frac{1}{2} v t$ per unit width of effective wheel-face, and this is limited by the power supplied to the machine. By the expression "effective wheel-face" is intended the amount which takes the cut; if the traverse $c$ lies between the half and the full width of the wheel- 
face, then the wheel-face tends to keep flat, and is effective over a width $c$, and the rate of removing material is $\frac{1}{2} v t c$.

The work done in removing metal by a single point cutting-tool in a lathe is approximately proportional to the volume of the material removed. Experiments upon cutting-forces show that this work increases as the section of the chip diminishes: a result to be expected, but the increase is at a slow rate. The chips taken in grinding are of very small cross-section-of the order of a thousandth of an inch both in breadth and thicknessand no experiments have been made upon chips of such a size, or taken with cutting points, whose facets are disposed so irregularly as those of an abrasive particle. The results above referred to may, however, be considered as applying to the case, leading to the conclusion that the work done in removing metal by a definite wheel is practically the same over usual variations of the depth of the cut, although it will actually be a little less with the heavier cuts. Also it leads to the conclusion that wheels of the larger grits will remove material at a slightly less cost in energy than wheels of the finer grits.

While no experiments have been made on the work of cutting metal, at the rate at which grinding chips are taken, the stressstrain curve can only alter very slightly if the rate of taking them be altered to the extent of the variation which the tangential component of the work velocity produces on the relative tangential velocity of wheel and work; it can only alter little, even over the variation of wheel-speed $(4,000$ to 7,000 feet per minute) used in practice. Hence the work of removing metal can only alter by very little with speed variations of wheel or work. Therefore the work done in grinding off metal is proportional to the volume removed-that is, the rate of grinding, $\frac{1}{2} v t c$, depends on the power used.

Hence for the work and wheel under consideration, the quantity vtc depends upon the power which is supplied to the machine, and cannot exceed a certain amount $b$, while for production reasons it is to be kept up to that amount. In use, a machine should not be run so hard that the power taken is close on the possible limit; this 
would lead to trouble sooner or later (for example, the machine might slow from belt slip), and $b$ is to be taken as the highest safe working quantity.

The Controlling Expressions.-There are therefore two conditions, $v^{2} t=a \frac{d \mathrm{D}}{d+\mathrm{D}}=e$ and $v t=\frac{b}{c}$, which serve to determine the values of $v$ and $t$ for any particular case, and they are sufficient for the purpose.

Checking Wheel Waste and Glazing.-They will indicate the procedure to be adopted in the various cases. Suppose that the wheel in use is wearing too rapidly. The first impulse is to reduce the cross-feed so as to lessen the intensity of the action, and check the wear by this means. The years of practical experience, however, have proved that it is better to reduce the work-speed, and that the wheel will then last properly, and this is generally recognized as the best modern practice. Another method advised is to reduce the wheel-speed, but this the Author cannot recommend. Inspection of the above equation indicates a somewhat different course to be the most advantageous.

As the wheel is wasting, $v^{2} t$ is too high and must be lowered. If $t$ be reduced, this is effected, but it is clearly more effective to reduce $v$. For example, if it were necessary to reduce $v^{2} t$ to $\frac{1}{4}$ its value to stop the waste, and $t$ alone were altered, it would be reduced to $\frac{1}{4}$ its value; while the same result would be effected by reducing $v$ to half its original amount. In each case the output is sacrificed as $v t c$ is lowered-to $\frac{1}{4}$ of its original value in the first case and to $\frac{1}{2}$ in the second, which is therefore the better. This sacrifice of output is, however, unnecessary. The problem is to alter $v$ and $t$ so that $v^{2} t$ is reduced to $\frac{1}{4}$ of its previous value, while $v t$ is unaltered. Solving the simultaneous equations, the result shows that $v$ must be lowered to $\frac{1}{4}$ of its original value, and $t$ simultaneously increased to four times its initial value. This stops the wheel waste, and at the same time keeps up the output.

Generally, then, the equations lead to the rule that if the trouble 
is wheel-waste, the work-speed is to be decreased far more than is sufficient to check it, and the cross-feed is to be proportionally increased; if the wheel still wears too fast, proceed further in the same manner.

Conversely, if the wheel glazes, the work-speed must be increased and the cross-feed simultaneously decreased so as to keep within the power limit.

Securing Maximum Output.--Suppose now that the wheel is behaving well, showing that $r^{2} t$ is correct, but that the machine can take more power, and hence give more output, then $v^{2} t$ is to be kept constant, but $v t$ increased. This can be done by decreasing $v$ in any ratio $k$ and increasing $t$ in the ratio $k^{2}$. For example, suppose that $v$ be lowered to $\frac{3}{4}$ of its initial value, then $t$ should be increased in the ratio $\left(\frac{4}{3}\right)^{2}$ (or by 78 per cent.), with the result that $v^{2} t$ would be unaltered, but $v t$, the amount ground off, would be increased in the ratio $\frac{4}{3}$ (or by 33 per cent.). And this is a general law, so that the slower the work-speed and the deeper the cut, the quicker will the stock be removed. Modern practice tends towards slow speeds, partly for the reasons shown above.

The question now arises as to where the work-speed reduction should stop, for the ultimate result is that, in order to remove the material at the highest rate, the whole grinding allowance should be removed by a deep cut at a single traverse. This is immediately opposed to one of the principles of grinding which give it the primary quality of accuracy-namely, that the stock is to be removed in small amounts, so that any gradual distortion of the work is minimized and the wheel-wear also rendered of no effect. The greatest permissible reduction of work-speed is therefore ultimately governed by the liability of the work to distort, but in practice no machine is supplied with nearly enough power for such a state of affairs to arise, and the limit is encountered much earlier by reaching the maximum value $(v t c)$ of the power supplied to the machine.

In finishing, the cross-feed must be exceedingly small (no mechanical feed finally), but practice differs considerably as to 
finishing speeds, advice that the ordinary speed should be increased and that it should be diminished being given equally. As the cut in finish grinding is exceedingly small, the normal material velocity will be small and the wheel will tend to glazing. This is desirable, as the wheel must not wear much in finishing; but nevertheless, as $t$ is so much reduced (to $\frac{1}{4}$ or so of its previous amount), $v$ may be safely increased (by 25 per cent. or more) and yet $v^{2} t$ will be much reduced. Finish ultimately depends upon the number of cutting points which have passed over the work-surface, and from this point of view wheel-speed and the truing alone count; from the principle above mentioned as to the securing of accuracy, an increase of work-speed is desirable, and also the required finish may be obtained earlier. The only factor militating against the increase of work-speed for finishing is the greater tendency to vibration, but this is small.

Effect of Work-Diameter.-Now that the manner of dealing with work of a definite diameter, ground by a wheel of a given diameter, has been considered, the effect of change of work-diameter and of wheel-diameter may be discussed. The equations $v^{2} t \frac{d+\mathrm{D}}{d \mathrm{D}}=a$ and $v t={ }^{b}$ must hold simultaneously, the first dependent on the wheel substance and the material ground, and the second on the machine. Dividing one equation by the other, the equation

$$
v=\frac{a c}{b} \times \frac{d \mathrm{D}}{d+\mathrm{D}} \cdot \text {. . . . }
$$

is obtained. It shows that the effects of wheel- and work-diameter are interrelated, and hence, in order to obtain some idea of the effects of variation, it is best to consider numerical cases.

Suppose that the work be 4 inches and the wheel 14 inches in diameter, and that for the machine in use it were found that a work surface-speed of 30 feet per minute and a diametrical reduction of $0 \cdot 00125$ inch gave the best results. If the wheel wore down to 10 inches diameter (being kept up to the initial surface-speed, usually 5,000 feet per minute) the question would arise as to whether any change should be made in the work 
surface-speed and in the feed. From equation (5), but substituting the original values of $v, d$ and $\mathrm{D}$, we have $\frac{a c}{b}=\frac{30(4+14)}{4 \times 14}$, and hence for the work-velocity with a 10 -inch wheel we have

$$
v=\frac{30(4+14)}{4 \times 14} \times \frac{4 \times 10}{4+10}=27 \frac{1}{2}
$$

so that the best work-velocity is little affected, there being only 8 per cent. difference, and generally the effect of the wear of the wheel on the best work-speed in external grinding is small. It may be noted that, if the same work-speed be preserved, the normal material velocity is higher and the wheel appears somewhat softer as it wears, and still more so if its surface-speed is not kept up to the value $\mathrm{V}$.

The work-diameter, however, varies more widely than the wheeldiameter and produces correspondingly large effects. Suppose that work of 1 inch diameter is to be ground, the work-speed would then be

$$
v=\frac{30 \times 18}{4 \times 14} \times \frac{1 \times 14}{1+14}=9 \text { feet per minute. }
$$

Since $v t$ is constant, $t=0.004$ inch. After calculating the values for work of 16 inches diameter also, the results may be tabulated thus :-

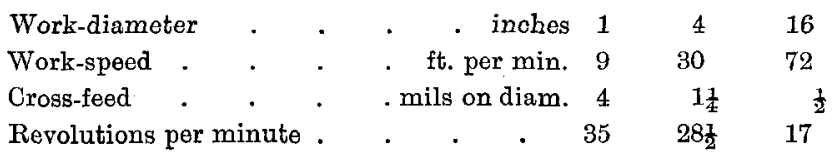

The surface-speed of the work therefore varies considerablymuch more so, in fact, than the rate of revolution does. Such large variation of work-diameter would hardly occur in practice, as the 1-inch and 16-inch work would be done on different machines, but it illustrates the point in question markedly. In practice the following difficulties usually modify these natural speeds.

Worle of Large and Small Diameters.-The force of the cut of the wheel on the work is the same in all these cases, and although the effect may be checked by steadies, this force will probably cause 
slender work to vibrate. In this case the force must be reduced, which sacrifices output and lowers vt. In order, then, to keep $v^{2} t \frac{d+\mathrm{D}}{d \bar{D}}$ constant, and the wheel under good working conditions, $v$ must be increased and $t$ lowered. The extent to which it is necessary to do this will depend on the flexibility of the work-it may only be little. From this result it is seen that work of small diameter should run at a lower surface-speed than larger work in the same machine, but that the tendency to chatter modifies the speed which can actually be used.

The large diameter work presents another point of interest. Here it will be noticed that the work-speed is so much higher that the cross-feed is reduced nearly to the amount of a finishing cut, and is such as can only well be used when the work is very true, and is therefore unsuitable for preliminary and general grinding.

Now if $v$ be lowered and $t$ increased in such proportions as to keep the normal material velocity unaltered, $v t$-that is, the power per unit width of wheel-face-is increased. The machine is supposed to be already in use up to the reliable limit of its power, and this leaves only one resource (apart from changing the wheel for one of a slightly softer grade), namely, to reduce the effective width of the wheel so as to concentrate the same power over a lesser axial space. This increases $\frac{v t}{c}$, and so permits a heavier and satisfactory crossfeed to be used with a lower surface velocity.

Narrowing the Wheel-Face.-The width of the wheel in full use may be reduced by lessening the traverse $c$, but as the number of traverse speeds is limited, and as the traverse should be between $\frac{5}{8}$ and $\frac{7}{8}$ of the wheel-face, this method is seldom really available unless the advantage of such a traverse be sacrificed and a lesser one (which tends to make the wheel-face wear convex) used. For a few articles this is best, but, for any quantity, the wheel should be changed for a correspondingly narrower one, and at the same time the traverse correspondingly reduced.

In addition to the want of original truth of work, rendering fine cross-feeds undesirable, they are difficult to maintain if the 
absolute distance between the work and wheel axes can vary (by spring of parts, etc.), as is especially the case in internal grinding. Furthermore, they afford little flexibility, and small variations and errors affect fine feeds proportionally more than they affect heavier feeds.

Surface Grinding.-If in the expressions 1,4 and 5 the workdiameter be supposed to be increased until it becomes exceedingly (infinitely) great, the work becomes flat, and the case is that of

ETG. 3.

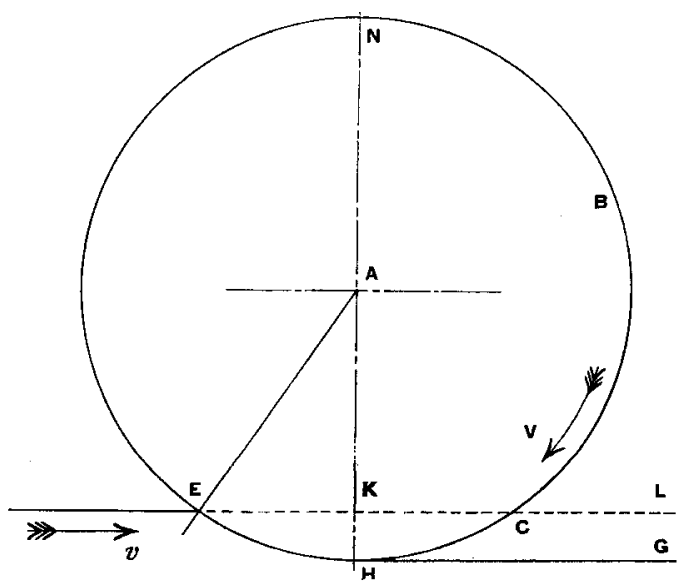

surface grinding with a disk wheel; and if it is supposed to vary further, changing its sign and diminishing, the case becomes that of internal grinding. The expressions of the various quantities then become :-

For Surface Grinding. For Internal Grinding.

$\begin{array}{ccc}8 & \sqrt{\frac{1}{2} \mathrm{D} t} & \sqrt{\frac{d \mathrm{D} t}{2(d-\mathrm{D})}} \\ a & \overline{\mathrm{D}} & \frac{d-\mathrm{D}}{d \mathrm{D}^{2}} t v^{2} \\ v & \frac{a c}{b} \mathrm{D} & -\frac{a c}{b} \frac{d \mathrm{D}}{d-\overline{\mathrm{D}}^{*}}\end{array}$


The negative sign in the last expression indicates that the direction of work rotation is to be reversed in internal grinding. In the other expressions for the internal case, the sign of $t$ is changed also. These values may be deduced from Figs. 3 and 4, using the same reasoning as previously.

Internal Grinding.-Passing by the case of surface grinding, the more interesting case of internal grinding is reached. Here both $d$

FIG. 4.

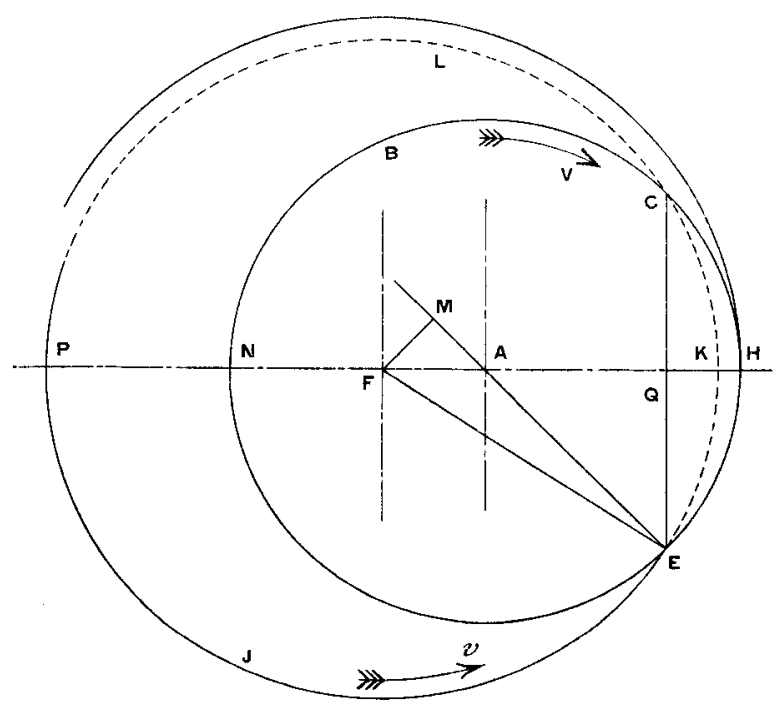

and $D$ vary considerably, but any change in either will usually produce a more than proportional change in $d-\mathrm{D}$, and hence it is an important factor. Its change as the wheel wears down in grinding a number of similar holes causes the chief difficulty in internal work.

Neglecting the sign of $v$, its value is $\frac{a c}{b} \times \frac{d \mathrm{D}}{d-\mathcal{D}}$, which can be calculated for any particular values of the work and wheel diameters by using the value of $\frac{a c}{b}$ derived from the previous example, 
provided that the internal grinder uses the same power per inch of wheel-face as the plain grinder does, and that a wheel of the same grit and grade be employed. Taking the case of a 4-inch hole (in the previous example the work was 4-inch diameter, but external), suppose that a wheel 3 inches in diameter be used to grind it. Substituting these values $v=\frac{30 \times(4+14)}{4 \times 14^{-}} \times \frac{4 \times 3}{4-3}=116$ feet per minute, and the corresponding value of $t$ is 0.00125 inch $\times \frac{30}{116}$, or $\frac{1}{3}$ of a thousandth of an inch; if, however, a wheel $3 \frac{1}{2}$ inches in diameter were used, the values would be $v=270$ feet per minute, and $t=$ 0.00014 inch. Thus when the size of the wheel approaches that of the hole, the difficulty of a very fine cross-feed again arises, for the springiness of an internal grinding spindle renders such a erossfeed unusable. As in the case of external work, the difficulty is to be met by increasing the power used per unit width of wheel-facethat is, by decreasing the width of wheel used. Reduction of the wheel-face, it is to be noted, does not directly imply loss of output, which mainly depends on the power utilized or on the total force of the cut.

Internal grinders are usually supplied with less power than plain grinders, for work of equal diameter, and this makes the wheel which can be used still narrower. The great disadvantage of a narrow wheel is that there is less grinding substance in it, so that the difficulties caused by the diminution of its size occur more rapidly.

Effect of Wheel-Wear and Size of Wheel. - The correct understanding of these difficulties is important as regards internal grinding, and they are shown most clearly graphically. In Fig. 5 (which is taken from the Author's book on Grinding, page 264) is shown the effect of change of size of the wheel in grinding work of 4 -inch diameter, the quantities being based upon those of the example taken, in which the power used would be about 2 h.p. per inch of wheel-face. Along $\mathrm{OA}$ is set off the wheel diameter, and along $\mathrm{OB}$ the work-surface velocity for the case of external grinding, the dotted curve OCD being obtained from the equation (5) 
External Work

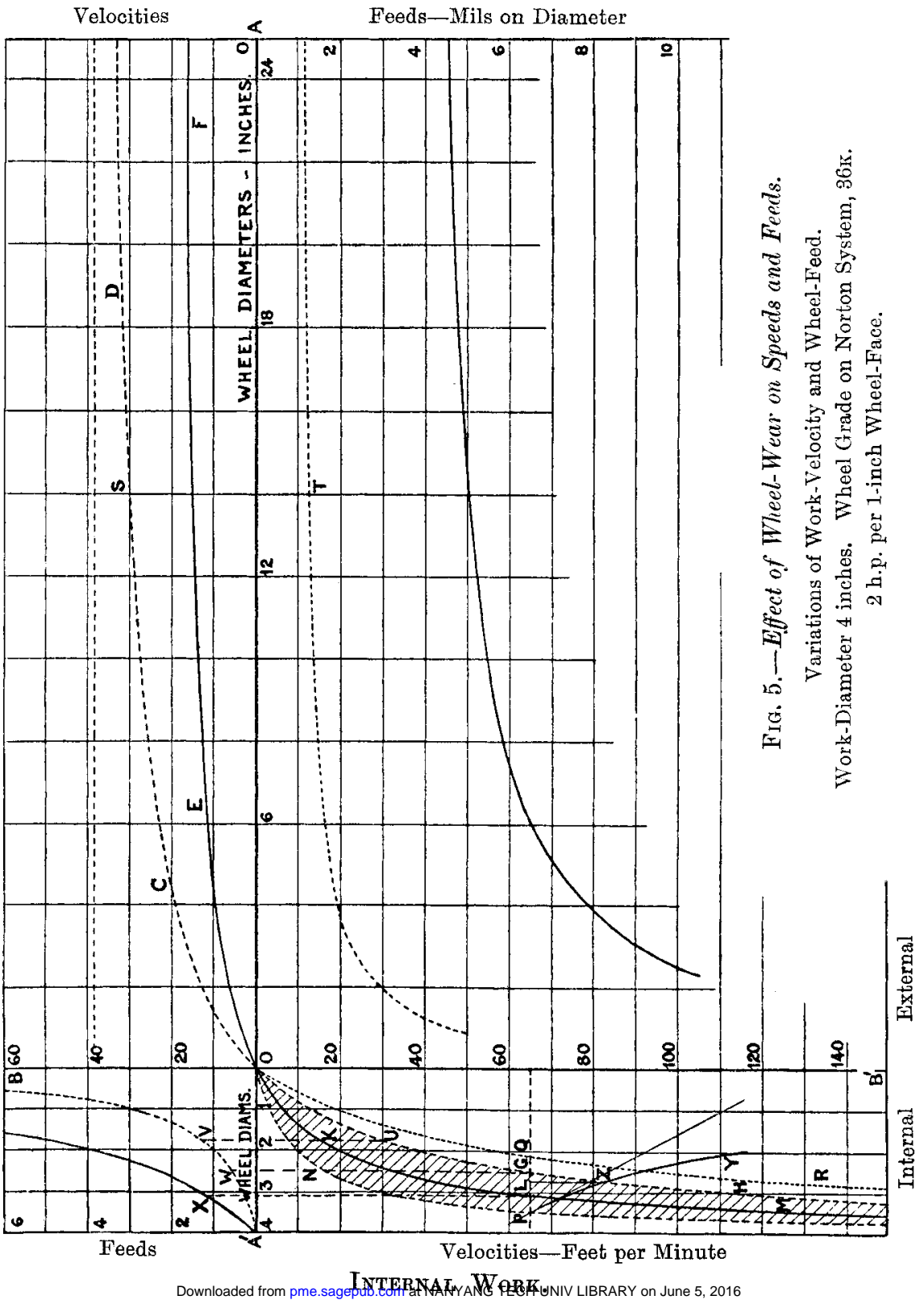


where $v=\frac{a c}{b} \times \frac{d \mathrm{D}}{d+\mathrm{D}}$. The corresponding feeds $t$ are set off downwards from the line $\mathrm{OA}$, the scale being given on the right of the diagram, and the dotted curve $\mathbf{T}$ so obtained.

The original 14-inch wheel required a work-velocity of 30 feet per minute, which would fall to $27 \frac{1}{2}$ feet per minute for a 10 -inch wheel, and to 23 feet per minute for a 6 -inch wheel. If a 24-inch wheel were used, the work-velocity would be 33 feet per minute, but however the wheel diameter were increased, the best workspeed would never exceed $38 \frac{1}{2}$ feet per minute indicated by the broken horizontal line, to which the curve OCD, a rectangular hyperbola, is asymptotic. If the same power were concentrated upon a wheel of half the width, the speed curve would be the full line curve OEF, and corresponding feeds would be given by the full line curve below.

The right-hand side of the diagram gives the case for external grinding, and shows that variation of wheel diameter produces little difference on the speeds and feeds suitable for work of a given diameter, and practically this small difference is covered by the range of the normal material velocity within which the wheel works well. The curves for internal grinding are shown on the left, $O A^{\prime}$ and $O B^{\prime}$ being the axes of wheel diameter and work-speed respectively. The curve OGH is actually a continuation of the curve DCO, but its inclination is very different, and it is asymptotic to the bounding vertical line, whereas on the external side it was asymptotic to a horizontal line.

The work-speeds and feeds for $3 \frac{1}{2}$-inch and 3-inch wheels have already been given, and it was observed that the feeds, which also may be taken from the dotted curve $\mathrm{A}^{\prime} \mathrm{WV}$ in the quadrant $\mathrm{BOA}^{\prime}$, turned out to be unworkably small. To remedy this, suppose that a wheel of half the face width be taken, so that 4 h.p. is now used per inch of wheel-face; all the velocities are now halved and feeds quadrupled, the former being given by the full-line curve OKL and the latter by the curve $A^{\prime} X$. A 3-inch wheel would now require a work-surface speed of 58 feet per minute and a feed of $\frac{4}{3}$ of a thousandth of an inch on the work-diameter in order to work at its 
best, and these would be usable. Now this full curve OKLM gives the best normal material velocity when 4 h.p. is used per inch of wheel-face, but actually there is a range, that between $\sqrt{2 a_{1}}$ and $\sqrt{2 a_{2}}$, which may be used satisfactorily. Suppose that halving its value would just not make the wheel glaze, and that doubling it would make it waste excessively (these are wide limits, and taken for the sake of clearness), the curve ONP then gives us the limit on the glazing side, and the curve OGH the limit on the wasting side, and the space between them represents conditions under which grinding can successfully take place.

All these curves, being derived from different values of $a$-that is, of the normal material velocity - are of the same type, passing through $O$, and being asymptotic to the bordering line. A curve OQR, shown in dots, would indicate a stage of very excessive wheel-wear. Now suppose that a surface speed of 65 feet per minute be given to the work; this is indicated by the horizontal line PLGQ, and the corresponding feed, indicated by the point $X$, is rather more than a thousandth of an inch. The point $P$, which gives a $3 \frac{1}{2}-$ inch wheel, is on the glazing line which indicates that a $3 \frac{1}{2}$-inch wheel would just glaze and any larger one would glaze badly. In grinding a series of holes the wheel would slowly wear down, and as it did so it would work better until--when the diameter was reduced to 3 inches-the point $\mathrm{I}$ on the full-line curve was reached, when it would be working at its best. Further wear of the wheel would tend to make it waste, until, when it had worn down to 21 inches, it would reach the point $G$ on the bordering curve, and be then wearing excessively.

The wheel can be used still further with the work at 65 feet per minute, towards the point $Q$, but the cross-feed must then be reduced to prevent the waste, and output will be sacrificed. The width PG thus gives the range through which a wheel may wear in internal grinding without causing trouble. Owing to its shortness the grinding regime alters rapidly, there being little range between glazing and wasting away. What is to be aimed at is to start with the wheel condition on the glazing curve, chamfering the edge if need be; as the wheel wears, it first works better and 
afterwards worse, and on reaching the stage of undue wasting the work-speed has to be lowered. If it be lowered considerably (e.g., from 65 feet per minute at $G$ to 15 feet per minute at $N$ ), it may be restored to the glazing condition again.

For the sake of lucidity, one factor has not yet been included, namely, the decrease in surface-velocity of the wheel, as its diameter decreases, for in the diagram the wheel surface-velocity is supposed to be kept constant, which would involve increasing the speed of the internal spindle frequently as the wheel wore downa case seldom provided for in internal grinding machines. The effect of keeping the wheel spindle-speed (instead of the wheel surface-speed) constant is to decrease the length of $P G$ or the amount of wheel wear before wasting. Taking a geometrical view, it is clear that the normal velocity must be proportional to the wheel surface-speed, and must therefore drop as the wheel wears down at constant revolutions per minute-that is, the limiting normal material velocity instead of being $\sqrt{2 a_{2}}$ must be $\sqrt{2 a_{2}} \times \frac{\mathrm{D}}{\mathrm{D}_{0}}$, where $D_{0}$ is the original wheel-diameter at $P$. Thus the boundary curve instead of being $v=\frac{a_{2} c}{b} \times \frac{d \mathrm{D}}{d-\bar{D}}$ (or OGH) will be $v=a_{2} \frac{\mathrm{D}^{2}}{\overline{\mathrm{D}}_{0}{ }^{2}} \times \frac{c}{b} \times \frac{d \mathrm{D}}{\bar{d}-\mathrm{D}}$, and by giving to $v$ its initial value $v_{0}$-the value at $\mathbf{P}$-this becomes an equation for $D$, and is easily solved algebraically. On the diagram, however, it is best solved by noticing that the elimination of $v$ between $v \mathrm{D}^{2}=v_{0} \mathrm{D}_{0}{ }^{2}$ and $v=\frac{a_{2} c}{b} \times \frac{\mathrm{D}}{d-\mathrm{D}}$ gives the same equation for $\mathrm{D}$. This, expressed geometrically, means that, by drawing the quasi-hyperbola $v \mathrm{D}^{2}=$ constantwhich has $O A^{\prime}$ and $O B^{\prime}$ as asymptotes-through $P$. to cut the curve $\mathrm{OGH}$, the point of intersection $\mathrm{Z}$ gives the wheel-diameter desired. Drawing the hyperbola or-what gives nearly the same result-its tangent at $P$, we obtain $2 \frac{3}{4}$ inches as the limiting wheeldiameter instead of $2 \frac{1}{2}$ inches.

Generally, if the surface-speed $\mathrm{V}$ of a wheel changes, the equation $v^{2} t=a \frac{d \mathrm{D}}{d-\mathrm{D}}$ becomes $\frac{v^{2}}{\overline{\mathrm{V}}^{2}} t=l \cdot \frac{d \mathrm{D}}{d-\mathrm{D}}$, since the normal 
material velocity must be proportional to the wheel-surface velocity. If wheel spindle speed remains constant at $n$ revolutions per minute, this gives $v^{2} t=k \pi^{2} n^{2} \times \frac{d \mathrm{D}^{3}}{d-\mathrm{D}}$. If the power taken still remains the same, $v t$ has its former value, $\frac{b}{c}$, which furnishes the second equation necessary for the determination of results. The elimination of $t$ for $n$ revolutions per minute then gives $v=\frac{k \pi^{2} n c}{b} \times \frac{d \mathrm{D}^{3}}{d-\overline{\mathrm{D}}}$, the same equation as has been found more directly for dealing with the special case of wheel-wear in internal grinding.

More closely calculated values of the wheel-diameters in the above example are, $3 \cdot 48$ inches at $P, 2 \cdot 51$ inches at $G$, and $2 \cdot 86$ inches at $Z$, so that $G$ shows a 28 per cent. reduction of wheeldiameter and $Z$ an 18 per cent. reduction.

Thus the difficulty of internal grinding chiefly consists in meeting the continuous change of regime due to the direct effect of the decreasing diameter of the wheel and to the secondary effect due to loss of wheel surface-velocity, and so far from the work velocity being kept constant, it is to be changed as often as necessary to meet the altered state of the grinding.

The Arc of Contact. - No reference has so far been made as to the effect of the length of the arc of contact in internal grinding; it is commonly regarded in practice as the cause of the trouble of the wheel behaviour. The Author has previously shown, however, that, owing to the proportional distribution of normal material velocity in the arc of contact, the actual length of an arc has no direct influence in grinding, provided that there is room between the abrasive particles of the wheel for the chips produced. Equation (1) gives

$$
\text { and } \quad \begin{aligned}
s & =\sqrt{\frac{D d t}{2(d \pm D)}}, \\
\quad s & =\sqrt{\frac{t^{2} v^{2}}{2 a}}=t v \sqrt{\frac{1}{2 a}} ;
\end{aligned}
$$

so that the length of the arc of contact is proportional to the power per unit width of wheel, or the area of effective contact (i.e., the 
length of the arc by the traverse) measures the power used at the grinding point and the output.

Effect of Grade.-Lastly, consider the effect of using a wheel of a different grade. The greater the amount of bond employed, the greater the force upon the cutting points which is necessary to dislodge the particles of abrasive and the "harder" the wheel is. It therefore will withstand, and requires, a greater normal material velocity to work well, and hence the work-surface velocity employed must be higher. The value of $v t$ for a given power-supply is less, because the particles get more blunt before they are dislodged.

Conversely with softer wheels, the speeds must be lower, and the output for a given power-supply is greater, which leads to their employment in order to secure the output, and hence to a further lowering of speed in modern practice.

Conclusion.-In the presentation of the Author's theory of speeds and feeds and the deduction of the methods for meeting the various difficulties, he has made use of as few properties of the wheel and work as possible, in order that the results shall be of very general application. In those cases where he has taken numerical examples in order to display the reasoning more clearly, the methods employed have been generally applicable, and the results may be considered to be typically representative.

The Paper is illustrated by 5 Figs. in the letterpress. 


\section{Discussion in London.}

The President, in moving a vote of thanks to the Author, said he did not profess to be an expert in the matter of grinding, and was quite prepared to say that there was a good deal in the Paper which was beyond his range of experience; but he had no hesitation in stating that, as far as he could judge, the Paper was one which really made a step in advance in one particular department of mechanical work, and he had no doubt it was really a very valuable Paper. It was not very easy to discuss, but he hoped there were engineers present who had had experience of grinding work, a work which was comparatively modern in its application, and extremely interesting. It had made immense way within a comparatively short time.

The motion was carried with acclamation.

Dr. H. S. Hele-Shaw (Member of Council) said personally he was in no sense an authority on grinding, though he had been a user of several grinding machines. The interesting point in regard to the Paper appeared to him to be that it was the birth of a theory on a most important subject. He had come that evening hoping to get one or two points elucidated. One point he could not altogether understand was the question of the importance of changing the work-speed by a comparatively small amount. If the work-speed were, say, 30 feet a minute, and it was changed to 60 feet a minute, it was changed 100 per cent.; but supposing the grinding wheel was run at 6,000 feet, which was not an uncommon velocity, and it was changed to 6,500 , the actual relative change of speed of the two surfaces was enormously greater than the change of 100 per cent. in the case of the work. There might be others who had had a difficulty in understanding why a change in the work-speed, which might mean only a small change in relative speed, made such an apparent difference; the velocity of the emery wheel could be changed to a very much greater positive extent, and therefore the 
(Dr. H. S. Hele-Shaw.)

relative velocities of the two surfaces were working in contact without apparently making nearly as much difference. The Author would be rendering a service if he would elucidate that point, which did not appear clear to most people who actually used grinding machines. He had written on the subject to a man who was certainly a high authority - the works manager of The Churchill Machine Tool Co., of Pendleton-and he had given an example of the great range that was possible in practice. That gentleman said : "I was recently consulted by a customer about the installation of a grinding machine for grinding a combined steel piston and piston-rod, the diameter of the piston being about $4 \frac{1}{2}$ inches and the rod $1 \frac{1}{8}$ inch. I informed him that both could be ground without a change either of the wheel or of the work-speed, and he was naturally incredulous. However, it was put to the test. Both sizes were ground efficiently without changing either the work-speed or the wheel, and as the piece of work had to be dealt with only in very small quantities, it was desirable that the work should be treated in this way. Naturally, if larger quantities had to be dealt with, it would have been advisable to have a grade softer wheel to grind a large diameter piston." That brought him to what Messrs. Churchill's manager considered a great point in the argument-that a very wide range of velocities could be obtained without affecting the result materially. It would be interesting if the Author would explain to the Meeting what he had told him privately, because his explanation made clearer than the Paper itself what the Author's views were as to the rate of approach of the wheel to the work. It was the rate at which the actual surface of the wheel entered the work that made all the difference in the comparatively small surface-change of the work. This matter of velocity and its effect upon the reduction appeared to be the whole substance of the Paper.

Mr. Guest, in reply, considered that the works manager of The Churchill Machine Tool Co. was justified in making the statement he did. The condition for grinding, irrespective of output, was expressed by the equation 4 (page 551). According to this, any value of $v$ could be used, provided that the machine could be made to give a 
corresponding value of $t$. As regards this point, he considered that machines were seldom fitted with a sufficient number of cross-feed rates; what was required was a duplicate ratchet which would give finer variations of the feed than the customary quarter-thousandths of an inch on the work-diameter. That was, instead of having one, two, three quarter-thousandths, the feeds might be one-quarter, three-eighths, one half-thousandth of an inch, etc. Messrs. Churchill's manager was correct in saying that the same rate of revolution could be used in grinding the two diameters in question-with corresponding cross-feeds. If a machine maintained so fine a crossfeed as would appear necessary, it would imply that the machine was substantial and well built. What mechanically determined possible fineness of cross-feed was partly the variations of the excessively thin oil-film in the wheel-spindle bearings and partly spring in the machine itself. With a springy machine it was impossible to maintain a fine cross-feed, and had the machine used been one with much spring it could not have done the work satisfactorily.

When taking advantage of this possibility of using a constant rate of revolution over a wide range of work-diameter, it was impossible to satisfy the equation $v t=\frac{b}{c}$ for the range, and accordingly output must be sacrificed. When, as in this case, the amount of work was small, output was justifiably disregarded, and the work could be done at the slower rate. When productive grinding was the matter under consideration, it was necessary to satisfy the second equation, and by combining it with the previous one, the correct work-speeds were fixed.

It would be noticed that the combination made the proper work-speed to depend on the power delivered to the machine. This was one of the reasons why the Author placed a weighted tension idler upon the beit from the counter-shafting to the spindle in his machines. For uniform results, it was necessary to make sure that uniform power could be obtained. A belt which had been tightened, either by taking up or by movement of the cross-slide of the machine, would convey more power than in its previously slack condition; the work-speeds to give the most rapid 
(Mr. Guest.)

results would then be slower than previously, and the conditions would vary. A device which maintained a fairly constant power, independent of variation in the belt condition and machine, enabled work to be done efficiently at regular surface-speeds, and generally avoided trouble.

The point raised by Dr. Hele-Shaw was not that usually raised in the shops, although it bore upon the same matter; in fact, these views were directly opposed. The ordinary view was that the surface-speed of the work was the important quantity and was the controlling factor, and was doubled if it were raised from 30 to 60 feet per minute. Dr. Hele-Shaw, however, pointed out that if the wheel were running at 5,000 feet per minute, and the workvelocity was directly opposed to it, the relative velocity had only been altered from 5,030 to 5,060 feet per minute, less than 1 per cent., which was an insignificant matter. This view was correct, and the Author regarded such a difference in the tangential velocity as without effect. Comparing a shaping machine and a planer, it did not matter whether the tool moved over the work or the work under the tool, provided that the speed of one relative to the other was the same. Cutting in a shaper at 80 feet per minute would correspond with cutting in a planer at 80 feet per minute. There might be a compound machine in which the work moved at 30 and the tool at 50 feet per minute, and if they moved to meet one another, there would still be a relative velocity of 80 feet per minute and the cutting conditions would be the same.

The variation between 5,030 and 5,060 feet per minute tangential velocity would make no practical difference, and in the Author's theory it was assumed to make none. Considering the bottom corner $\mathbf{E}$ in Fig. 2 (page 548) of the are of contact, it could be seen that there the work had a velocity which was not merely tangential to the wheel-edge, but had a component normal to the wheel-edge, along EA. This normal (material) velocity could be calculated in any case from equation 2, and was the controlling factor in the grinding. If the wheel surface-speed (V) varied, it was the ratio to this of the normal material velocity $\left(v_{1}\right)$ which was the effective quantity (see pp. 564, 565). 
The President said he was sorry there had not been more discussion on the Paper. He knew that the Author had given very great attention to the whole question of grinding, and, although he himself was not in the least an expert, he thought he might say with confidence that anyone who had a great deal of grinding to do might trust the Author's opinion as to the manner in which the work could best be done.

\section{Discussion in Manchester.}

The Chairman (Mr. Michael Longridge, Vice-President) in opening the discussion said the way in which the members had received the Paper and the Author showed their appreciation of both. Not very long ago grinding was considered a luxury, only to be employed when extremely accurate dimensions or very fine finish was-necessary, but he supposed that, in these days of highspeed lathes and turret lathes, the grinder was almost a necessary adjunct to the first machine. Grinding, so far from being a luxury, was now, he understood, the most economical way of turning out good work. If this were so, the Author had set himself a very useful task, for in a problem where there were so many variables-the hardness of the bond, the size of the grit, the speed of the work, the speed of the wheel and of the feed-he thought it was hopeless for anybody to try to find out by groping experimentally what was the right thing to do. He did not know whether the formulæ given in the Paper were right or wrong; he could not quite follow them ; but supposing they were right, or approximately right, they provided means of bringing order out of confusion by correlating all the variables and so enabling one to get a very good idea of the effect of changing each. That was very well illustrated on the discussion of the values of $v t$ and $v^{2} t$ on pages 553-4. The curves at the end of the Paper were equally valuable.

He hoped the members would not only express their opinion on the Paper, but would also give the results of their own experience. 
(Mr. Michael Longridge.)

When the Paper was read in Iondon he was afraid there was no one present capable of discussing it; they had come to Manchester for the opinions of grinders who could give advice based on practical experience as well as on theory.

Mr. Hans Renold heartily thanked the Author for bringing forward a subject of such importance at the present time; and no less he congratulated the Institution on having taken steps to bave such a Paper read in Manchester. It had been said, and he thought truly, that the quantity of soap used in a country per inhabitant was a measure of the degree to which it had advanced in civilization. No less truly, he thought, could it be said that the quantity of emery wheels used in an engineering establishment, in all its multitudinous operations for removing metal, was a measure which showed whether such establishment was in the forefront of progress or hopelessly lagging behind. In England, he had no doubt, grinding operations in the manufacture of machines were not used to the same extent as one found in America, Germany, Switzerland, or Sweden. Only the previous week he had seen in Zürich some wonderfully accurate and expeditious work done by a special grinding machine, which enabled the Swiss to produce a kind of high quality work unattainable here.

He was rather struck by the boldness of the Author trying to put his experience and practice in the grinding line into such precise and definite formulæ, because his own experience was rather that there were so many constantly altering conditions entering into any grinding operation that no rules, except of a very general nature, could be laid down. Still, if this modern method of removing metal, either in large, small, or very minute quantities, was to be adopted, there ought to be no difficulty in learning how to do it, if the subject were approached in a sympathetic spirit and it was borne in mind that speed, feed, and methods were very different things from what the ordinary mechanic was accustomed to when working a lathe, milling, or shaping machine. A little common sense and power to observe rightly how the results differed when changing the grade of his wheel, its speed, and the feed which 
the nature of the work would allow, would help an operator much more than the formulæ the Author advanced so profusely.

In a modern engineering establishment, grinding might be divided into three large groups:-

(1) The sharpening of cutting-tools, such as were used on lathes, milling machines, reamers, or any revolving cutters with two or more cutting edges. Although for sharpening lathe tools a simple grindstone might do, this was no longer the best method when great quantities or accurate grinding of revolving cutters were to be done.

(2) The finishing of hard or soft machine-pieces to a degree of exactitude. By the help of this class of grinding machine, or, as the French more correctly called them, "machines à rectifier," the machinist could now produce machines capable of running at such high speeds as were never possible before the introduction of these finishing machines by grinding. The speaker referred to one such grinding machine in his establishment, which had a grinding spindle running at 120,000 revolutions per minute. It was used for finishing die-holes as small as half-a-tenth of an inch. The grinding wheel, if it might still be so called, was a soft steel wire impregnated with diamond dust.

(3) This group was for doing manufacturing work, where metal was removed by grinding more expeditiously, nearer to size, of a higher finish, and at less cost than was possible by any other methods.

Whilst the Author had tried to give much information by formulæ about wheel-surface speed, work-feed and cross-feeds, for internal and external grinding, the speaker thought that but little use could be made of these mathematical expressions by a grinding operator. All these factors had constantly to be altered according to whether the grinding wheel was soft or hard, of a coarse or fine grain, free or hard cutting. These factors had again to be altered 
(Mr. Hans Renold.)

when the work was frail, and could not be well stayed, and would not allow of what was called a full cut. Many grinding machines -in fact, nearly all-were of too light a construction, and fullspeed productions could not be obtained. One of the greatest authorities on grinding-Mr. Norton, of the Norton Emery Wheel Co.-was of opinion that there was hardly a formula or rule which expressed the method by which the best and greatest output could be obtained. To obtain this a man with common sense was required, who had great expectations of what could be done by grinding wheels, who was willing to try different methods and combinations of wheels, speeds, feeds, etc., and who was capable of rightly observing the results and adopting whichever he found best. The Author mentioned at the end of his Paper that much depended also upon the correct construction of a machine, whether or not it was stiff and heavy enough to allow a good cut to be taken.

Some twenty-five years ago he (Mr. Renold) had an interesting experience with a Universal grinding machine-one of the best built in those early days - which was perhaps worth mentioning. The emery-wheel stand was on an overhanging knee, cast on a stiff machine body, but still it was overhanging. This machine could never turn out a job as good as desired. One day two ironstays were made, 2 inches by $\frac{1}{2}$ inch, and this bracket was stayed from the base of the machine. When this was done the machine was much more rigid, and the work turned out was as good as could be desirèd.

As already intimated, he would like to see more grinding operations adopted, and he hoped that no one present would be frightened by the formula given in the Paper. Grinding might, in fact did, at first present some new and often baffling problems; still, if tackled with sympathy and determination, there would be ample reward. Grinding machines worth having could not be made too good, and therefore first-cost cheapness must not be expected from this type of machine.

Before he left his works that evening, he had procured a few figures which might be of interest to some of the members 
present. These figures were apropos of the proportion of the number of grinding machines to those of ordinary machine-tools used in his works. In his factory there were 980 machine-tools, of one kind and another, and, along with those, there were 147 grinding machines. This gave, for every 100 machine-tools, 15 machines on which metal was removed by the help of a grinding wheel. These 147 grinding machines grouped themselves about as follows :-

One third for sharpening cutting-tools.

One-third for rectifying and finishing tools and machine parts.

One-third for manufacturing machine parts, namely, removing. metal.

He thought it might be news to some of those present that in Birmingham there was a large firm which finished the $3 \cdot 3$-inch shells by grinding instead of turning in the ordinary way in a lathe. Broad emery wheels were used, and shaped exactly to the form of the shell, including the nose. It was claimed that by this method better and quicker work was done. He thought that this was a claim on behalf of grinding which he could hardly support, especially when the rough finish required for a shell was considered.

In manufacturing grinding operations, such as making highlyfinished calender bowls for all sorts of purposes, also grinding of railway axles and wheels, rolling-mill rolls, etc., large grinding wheels were now used, even up to $2 \frac{1}{2}$ and 3 feet diameter and 12 inches wide. Such wheels were mostly driven by special motors mounted on the grinding spindle. The more usual-sized wheels of 14,18 to 24 inches in diameter for doing heavy manufacturing work could seldom give the utmost production when driven by a leather belt, however wide it was made. In his own works some twenty specially constructed wet grinding machines, of different sizes, could not be made to give the best work and in greatest quantities until all medium and larger machines were driven by chains; so that the speeds of these chains could be kept within reasonable limits, the diameter of the grinding wheels was kept fairly large. 
(Mr. Hans Renold.)

Mr. Guest, in his formulæ, warned them not to make the wheelspeeds too high, but he (Mr. Renold) had never found any difficulty from wheel bursting at very high speeds. A grinding wheel well bonded, free cutting, reasonably used, and above all carefully and truly mounted, would stand a very high surface-velocity. A still higher speed could be given to a compound wheel made of a series of sticks fixed into a circular steel ring in such a way that the higher the speed the more these sticks would wedge into their places, where they were thoroughly supported in a cradle. A grinding wheel thus made could run 50 per cent. higher than a solid disk-wheel. Such a compound wheel had clearing spaces between the sticks and could do more heavy work than a solid wheel. The chips came off like fine turnings, looking like a bunch of fine waste. Such work could only be done when everything was right. The power must be there, the wheel-speed right, the water plentifully supplied, the work-feed right, and the machine stiff, and all gliding and running fits accurately made.

The power required for a grinding wheel might be anything from one-tenth to 20,40 and even 100 h.p. He (the speaker) had seen, some three years ago, a machine for grinding railway-axles, with the chilled wheels ready mounted, and some four grinding wheels were at work at the same time. There was about 250 h.p. on this grinding machine. To drive light ordinary size grinding machines, there was no difficulty with well-jointed leather belts, but when 14,18 or 24 -inch diameter wheels by 2 or 3 inches wide were used, as often was the case for manufacturing purposes, then no better medium than chains could be found for driving. With such a drive, the power and speed, once provided for, was there and could be depended upon whether the grinding cut were heavy or light. There was no rise in the temperature of a running spindle caused by the slipping of a leather belt, and therefore the bearings could be made a much better fit, without which no grinding machine could possibly give good results.

The Author also alluded to the glazing of grinding wheels depending upon the speed of the wheels. He (Mr. Renold) could not altogether agree with the Author on this point. He always 
understood that the speed might be quite right, still glazing would sometimes take place. Such glazing would be caused by the used-up particles of the wheels not falling away or wasting fast enoughthat is to say, after the wheel grains had done their work and lost their sharp cutting corners, they should break off, and the wheel present fresh sharp-cornered grains to the work.

Mr. W. H. Cook, referring to the remark of Mr. Renold about the rarity of grinding correctly, said he could mention the name of a firm in the district where grinding had been done for very many years as accurately as in any part of the world. He had seen, some years ago, two large diameter rollers 100 inches long, which, after grinding, were pressed together, the ends being made up with clay to form a well, and water then poured in, and there was not the slightest trace of the passage of water between the two after several days. This was a fine test.

He was of the same opinion as Mr. Renold, that if too much notice were taken of the mass of formulæ, any one who had had no experience of grinding machines would be inclined to say it would use up too much of his brain power to install it, and he would therefore do without it. Fortunately, he had had considerable experience in the use of grinding machines, otherwise he might say the same himself. There were some people to-day who were advocating the use of grinding machines to remove heavy masses of material; he himself had never known such a procedure to pay, either in time or general financial results. The best course to pursue was first to have lathes of sufficiently heavy design, particularly in the front necks of the fast head, and to turn the work as near true as possible, leaving a few thousandths of an inch for the grinder to finish true and correct to size.

In the Manchester district certain machine parts had been ground in very large quantities per week for more than thirty years at a low price, exact to diameter, and with a satisfactory finish, and in dealing with one of the works doing this his experience had been quite different from what was stated in the Paper. In many cases it was found that whatever change was 
(Mr. W. H. Cook.)

made in speed or feed the wheels would glaze or wear unduly; it was only by making continued experiments with different kinds of wheels and with varying speeds and feeds that the best results were obtained, and then no changes were allowed, no matter how cheaply other wheels could be bought.

Another difficulty he had experienced was the jars in small castings arising from the method of suspension. He had never found satisfactory work with one centre revolving and the other fixed; both should be dead centres. There were other difficulties which arose, but after a time experience showed how they should be overcome. One great reason why grinding was not more generally adopted, except in very high-class work, was the high price of the machines. When a machine which could be carried on one's shoulder cost from $£ 80$ to $£ 100$, the question of its adoption became prohibitive in many instances, and it would be to the interest of some maker to design a machine which would suit the general trade at a more reasonable price. In concluding his remarks, Mr. Cook asked the following questions: (1) How could Mr. Guest's formula apply to two wheels of different composition? and (2) Would he use the same formula for all kinds of materials -brass, cast-iron, or steel?

Mr. H. H. Asbridge said that, as one who had been interested for some years in the manufacture and design of grinding machines of the type referred to in the Paper, he would like to make a few remarks. In the first place he would like to thank the Author for his courage in bringing the subject forward, more particularly in view of the scarcity of data relative to it. He had read the Paper carefully and followed the theory as developed, and he thought that a more correct title would have been "The Theory of Grinding, geometrically considered." There was no doubt it could be conceded to be correct when viewed from the geometric standpoint as to the interaction of the wheel and work-surfaces shown in diagram form in Fig. 2, and so ably analysed by the Author, always assuming, of course, that there was interaction - that was, a definite amount of cut or reduction of work-diameter. 
In order to develop his theory, the Author had had to assume certain factors as constant, those being the material operated upon and the grinding wheel. Admitting that these were constant in individual cases, and following the theory to its logical conclusion, one would have first to find the best and most suitable surface-speed or velocity of work, also the maximum cross-feed the work or the wheel would stand. This, of course, was done in actual practice. When those two factors were obtained, equation 4 (page 551) was formed. Using this as a basis, the correct work-speed and cross-feed for other diameters of work could be calculated as in equation 5 (page 555) and examples given on page 556. Considered geometrically from the basis of the constant area of ground-away portion, due to the interaction of wheel and work, it might be correct, but it was not borne out in practice.

Even if it were admitted that the work-speed should be varied proportionately according to its diameter, there was always present the danger of vibration in heavy large-diameter work, which was difficult to control. Conversely, in the case of small diameter work it was essential to have a higher work-speed than that given by equation 5 , in order to distribute the stress of the wheel-cutting action, and also-what was more important-to distribute equally throughout the ground portion the excess heat generated and not carried away by the cooling water.

Why should the Author, in developing his theory, adopt the basis of variable work-speed and proportionately variable cross-feed when, by keeping both those factors constant, the same effect could be produced? It should not be assumed from this that the constant work-speed must be absolutely invariable, but the word constant was used relatively in combination with a certain grade and speed of grinding-wheel, and as determined, it would be constant over a certain range of work-diameters, as the primary governing factor in the adoption of any work-speed was the grinding wheel, and the work-speed might be anything from, say, 20 to 100 feet to give efficient production.

If reference were made to the Table on page 556, wherein pieces of work of 1 inch, 4 inches, and 16 inches diameter were 
(Mr. H. H. Asbridge.)

compared, using the same diameter of wheel, the 1 inch and 16-inches being deducted from the 4 inches diameter basis, and which might be taken to be correct practice, it was found on working out the examples that the cubical contents of the material removed per minute were practically identical in each case, and, viewed from that standpoint, conld be taken as proving the theory or the formula to be correct. But, examining the examples given from the practical standpoint, the 1 inch piece of work could not be ground successfully at 9 feet per minute with 4 thousands in diameter cross-feed. The machine and the grinding wheel would stand it, but the work would be distorted.

If they examined the examples further, and assumed a constant work-speed of 30 feet per minute, and a constant cross-feed of 11 thousands on diameter, they found that the cubical contents of material removed per minute were exactly the same as given in the Table, but there was this difference, that the 1 inch piece of work could be successfully ground at 30 feet per minute with $1 \frac{1}{4}$ thousands cross-feed, because at that speed the heat generated could be better distributed and dissipated. In order to prove that, he had prepared two sample shafts 1 inch diameter by 12 inches long, one being ground at 10 feet per minute and 4 thousands diameter cross-feed, and the other ground at 27 feet per minute at $1 \frac{1}{4}$ thousands per diameter cross-feed. These speeds were the nearest obtainable on the machine. $\frac{1}{3 \frac{1}{2}}$ inch diameter was ground from both shafts, the traverse being the same per revolution of work. Both shafts took four minutes each, and both took 5 h.p. net. The inspector's report on the shaft ground at 10 feet was as follows:-

"Shaft discoloured and shows deep traverse lines 0.002 big in centre."

On the shaft ground at 27 feet:-

"Finish fairly good, shows slight traverse lines and 0.002 large in centre."

This test showed that while both shafts had been subjected to the same work in the same period of time, the higher work-speed came out best, and if a still higher work-speed had been used with a proportionately smaller cross-feed so that the same amount of 
material was removed in the same time, the result would have been better. Both tests were made on a powerful machine, and under a flow of water of 40 gallons per minute. That might or might not be taken as conclusive that the theory of grinding should be developed on a basis of constant work-speed and constant crossfeed in order to maintain a constant production, but it indicated that it was logically the correct method. (See page 587.)

Professor A. B. Field said he had not had an opportunity of giving to the Paper the consideration it deserved; but he felt that he was justified in congratulating the Author upon running the gauntlet of criticism and introducing the formulæ. After all, if a great deal of trouble had to be resorted to, to get the best results, it was one step gained to have a guiding line, to enable the practical results to be properly co-ordinated and compared. From that point of view, it seemed to him that an investigation of this kind should be most useful.

He would like to ask whether the question of the heating of the work would not sometimes limit the considerations that Mr. Guest brought forward. The general heating of the work was small in this class of machining; but, on the other hand, with heavy cuts and comparatively small work-speeds, local heating might occur, and, in consequence, small distortions of the work; thus the final piece, particularly when unsymmetrical, would be affected by these temperature changes. He imagined that considerations of this sort would influence the formulæ, and that really the Author was simply aiming at a general guide to the relations of speed, time of cutting, and so forth.

With regard to the ultimate bursting strength of the disk, it would be interesting to hear from the Author, or other practical grinders, whether the relations that usually obtained in the case of a rotating disk having some ductility held similarly in the case of such a bonded material as these corundum wheels. Burst wheels were doubtless rather rare, but the information obtained from such cases, where the bursting was not due to flaws, should be of value. 
Mr. Guest, in reply, said that the particular value of grinding was that it produced accurate work economically which was useful for two reasons: first, that it gave very much better wear, durability, and running in the product; and secondly, that it saved erection costs considerably. In making press and running fits along the same shaft there was little doubt as to the saving effected by grinding. Mr. Hans Renold had pointed out that in the case of a cup-wheel very long chips were produced. Disk-wheels could not produce long chips, as the chip-length was controlled by that of the arc of contact which was always short, but with a cup-wheel the chip-length could be almost half the circumference of the wheel, and one of the smaller difficulties in cup-wheel machines used for manufacturing was that the chips formed a swath which was rather difficult to get away freely; it was like steel wool, and if the spaces in the machine were not large, clogging was apt to occur.

Glazing, as Mr. Renold said, was due to the rubbing down of the fine projecting points of the wheel-surface. This was taken for granted in the Paper, the cause being assigned to a too small normal material velocity. The wheel consisted of particles of abrasive held in cement, and looking at the surface of a modern wheel one saw that it was comprised of particles, between which were comparatively deep hollows, within which were other particles. In the action an outside particle encountered the work along the are HE, Fig. 2 (page 548); at $H$ it merely rubbed, but at $\mathbf{E}$ it cut heavily. The particles a little lower in the wheel than these rubbed at points such as $Q$, then cut a little, but did not take such large cuts as the outer particles. After a while the outer particles would be broken or torn out of the wheel, and the full action would be taken up by the next set, but the previous action would have already dulled the points of these somewhat. If the force produced at $\mathbf{E}$ were insufficient to dislodge the outer particles, they would gradually become more blunt until the surface of the wheel was comprised of polished facets and looked shiny. It was then quite glazed and would not cut. There was a certain amount of energy stored in the machine and wheel, and by suddenly increasing the cross-feed it could be utilized to break up the face of a glazing- 
wheel. When it was observed that a wheel was beginning to glaze, that should be done immediately and the work-speed then lowered. It was necessary to do this before the glazing was in an advanced stage, else the wheel-surface would be so smooth as to prevent the course being effective.

Mr. Renold mentioned that sometimes the wheel got clogged up with material from the work, and referred to this as glazing. It seldom occurred, and was technically termed "loading." The tendency was greatest with copper and such tough materials, and the best course was to rotate the work fast, taking a light cut.

Mr. Cook also referred to difficulties caused by glazing. If the wheel were quite unsuitable, it was necessary to change it. More power was needed for the use of a hard wheel than for a soft one, but the harder wheel would last longer and would do more work as each particle had to be blunted more before the cutting force tore it from the wheel. The hard wheel itself would thus be the cheaper if wheel price alone were considered; including power cost there was little difference, the further inclusion of labour costs generally showed the softer wheel to be the more economical. The growing use of such wheels was another reason why modern machines tended to use slower work-speeds. The seller would use and offer the softest wheel he could, so as to obtain the greatest output from the machine. The worst feature of the use of hard wheels was the greater heating effect.

Mr. Cook then referred to vibration, and said that it might be stopped by changing the wheel. Vibration effects were difficult to treat; they almost invariably arose from some rapidly rotating part being out of balance. The forces produced by a small want of bajance in the wheel were considerable, because of the high speed; thus a want of balance of one ounce at a foot at a speed of 1,200 r.p.m. caused a force of about $30 \mathrm{lb}$. weight, changing its direction twenty times a second. If there were any period of free vibration in the work or machine approximately the twentieth of a second, the force would have a cumulative effect and soon produce marked results These vibration effects were important in all high-speed machinery; the shafts of some fine woodworking machinery upon which the 
(Mr. Guest.)

Author was engaged had to be balanced to a quarter of an ounce at six inches. As want of balance in a wheel might so easily produce vibration, changing such a wheel for a balanced one should be tried when vibration gave trouble. Wheels were frequently balanced by the makers by the insertion of lead at the central hole. The wheel would then run well until worn so that the defective part was removed, when it would be out of balance. When a firm used a large number of wheels, it was well to balance them on ways occasionally.

He preferred to refer Mr. Cook's statement as to the prices of machines to someone else; but he did not think it possible to build such accurate machinery cheaply. A machine which would regularly give the accuracy demanded in modern manufacture must be very well built, and the question was whether it would pay at the price asked for it. It seemed to him that if the work were produced rapidly by comparatively unskilled labour without any trouble, the price of the machine was a secondary consideration. The cost of labour and delays were the principal items in manufacturing expenses.

Mr. Asbridge inquired as to the effect on the equation of variations in the material ground and of the wheel, and he appeared to think that the formulæ applied to some definite material and wheel only. A formula bearing upon any physical phenomena would contain certain constants (such as the gravitation constant) dependent upon the particular case. To cover the changes of work and wheel material, two constants might be expected to be necessary, but actually only one was needed- $a$ in equation 4 (page 551). All variations, both of work and wheel material, were covered by changes in this constant. In all, three constants were used : in the second equation there were $b$, which was proportional to the power used (but its value was affected by the grade when the wheel was changed), and $c$, the traverse or width of wheel-for in grinding practice the amount of traverse must lie between $\frac{6}{8}$ and $\frac{7}{8}$ of the wheel-face, otherwise the wheel would wear convex and produce on the work a very shallow helical track, the appearance of which was objectionable. The constant $a$ depended only upon the material of the work and upon the wheel substance; for cast-iron it had a value rather more 
than twice as great as for steel, and if the wheel used were changed for one a grade harder, the value of $a$ would be lessened from 10 to 15 per cent. Thus $a$ was a definite constant when any particular material was being ground by a wheel of a certain material and quality, but its value changed when either wheel or work material was altered. By this variation the formulæ applied to all cases.

The results of the two trials on grinding 1-inch bars showed that the value of $a$ in the case was such as to make the higher work-speed the more suitable of the two tried, but they were insufficient to ascertain the best value of the constant. At the slower speed the work was burned, which showed that the wheel was glazing. This supported the Author's theory, as it showed that raising the work-speed and reducing the cut, keeping the output constant, checked glazing.

Mr. Asbridge thought that the Author's theory was geometrical only, but this view was erroneous, and probably arose from the Author's separation (page 545) of the geometrical and mechanical sides of the problem. The intimate connexion of these views and the interdependence of the geometry (pages 546, 548-9), and the force effects (pages 547, 550-1) involved, lead to the theory advanced. The geometrical motion determined the sectional area of the chip taken by the points of the abrasive particles, this area determined the force upon the particle, this force determined whether the particle was going to be broken or torn out of the wheel, or whether it would remain in it and glaze, and thus the whole action was determined. If the theory were geometrical only, geometry alone would be necessary for its absolute proof.

Mr. Asbridge stated that he upheld the usual view that the work-surface speed should be constant, and asked, "Why develop a theory upon the basis of variable-work speed and feed?" This question indicated a misconception of the nature of the Paper. To take any variable (or constant) work-speed as a basis would not be a theory, it would be termed an assumption-it might be a useful one. Such was the common view that the work-speed should be constant. It was the failure of this assumption to meet the 
(Mr. Guest.)

case that first led the Author to investigate the matter. Any physical theory must be based upon the known properties of the bodies employed; to obtain workable theories, properties or actions having small effects have almost always to be neglected. This was the case in that set forth by the Author, and upon some of these points he had particularly desired the opinions of those present. Proceeding thus from certain bases, the Author arrived at the conclusions as to work-speed which were given in the Paper-that is, the work-speed rules were not assumed but rationally deduced.

As regards the vibration of heavy pieces of work, this was a phenomenon usually regarded as mysterious in the shops. The vibration of slender pieces, having a comparatively slow free period, seemed to most a natural occurrence. The vibration occurring with heavy pieces of work was due to the slowing of a free vibration period in the combination of machine and work, by the increase of the mass of one portion--the work. When the period approximated to a forced period there would be appreciable vibration. The effect produced upon the vibration period of a shaft by fixing a heavy pulley at its centre, and the lowering of pitch of a tuning fork by weighting the ends, were examples of this lowering of periods by the addition of mass.

Professor Field asked about heating the work; it was an important point. The work was heated all the time and just at the surface was raised to a high temperature. Calculation and the examination of the chips showed that fusing of the metal occurred when the cut was heavy, and the Author considered that to be the chief reason why there was so little difference between grinding steel when it was hardened and when it was soft. It was sometimes found that the surface of ground hardened steel was not as hard as it should be; if this were due to loss of temper in grinding, the careful removal of a few thousandths would reveal a surface of the correct hardness. All hardened work should have the last few thousandths ground off with a very fine feed, for this reason.

In precision grinding the bursting of a wheel was an exceedingly rare occurrence, and the accidents had almost invariably been 
traced to some damage to the wheel not arising from its normal use. The value of Poisson's ratio for wheel material was not known, and so strength formulæ involving it were not applicable. The dimensional proof (in the Author's book) that the stress depended upon the peripheral velocity only, took the wheels to be of similar shape, but the approximation was near enough for practice. The strength and permissible speed increased with the harder bonds (see page 588).

\section{Communications.}

Mr. H.H. Asbridge wrote that, since speaking at the Meeting he had carried through some further tests, with a view to determining the best work-surface speed over a range of shaft diameters from $1 \frac{1}{2}$ inch to 6 inches, under as nearly as possible constant conditions, and regardless of finish obtained. The tests were carried out on a selfcontained electrically-driven Churchill plain grinding machine, and, specially for the test, both the work and the wheel were driven by independent motors connected with large ammeter dials reading directly in horse-powers, the intention being to record the power used on each. It proved, however, that the difference between the work-drive, when running light and when cutting, even on the large diameters, was so infinitesimal that it was neglected.

The method adopted to keep the cut constant was to bring the wheel directly on to the work, and operate the cross-feed so as to maintain the horse-power constant during the period of the test, the figure determined upon being $10 \mathrm{h.p}$. over that required to drive the wheel when running light; 30 h.p. was available, but a maximum reduction was not aimed at. No traverse motion was used. The work-surface speeds aimed at were 60, 40, 20 feet respectively, but as these could not be obtained exactly on the machine, the nearest possible were used. All the tests were carried out in duplicate, the grinding wheel being frequently trued to maintain as constant a condition of face as possible. The results were given in the accompanying Table, the material removed being 
(Mr. H. H. Asbridge.)

the a verage of the tests. The efficiency was also given both for each diameter of shaft in relation to the surface-speed used, and the material removed, and also for the range of shaft diameters.

It would be noticed that the efficiencies on each test were the highest for the highest work-speed adopted, and were very consistent throughout the range, the 4 inches diameter being the lowest; the efficiencies for the slowest speeds fell consistently as the diameter of work increased, and would indicate that the workspeed for small diameters had very little effect on the ultimate result, but the higher speed would be preferable for reasons mentioned earlier. On the larger diameters the correct work-speed was evidently of much more importance, and a surface-speed of 60 feet per minute or over would apparently be the most efficient. It would be interesting to have the Author's comments on the results tabulated.

Grinding wheel : 26 inches diameter, 3 inches wide. 6,000 feet per minute surface-speed. Work-surface speeds: 60,40 and 20 feet per minute. Mild steel shafts : 0.35 car.

\begin{tabular}{|c|c|c|c|c|c|}
\hline Diameter of shaft tested . . & $1 \frac{1}{2}$ in. & $2 \mathrm{in.}$ & 3 in. & $4 \mathrm{in.}$ & 6 in. \\
\hline Surface-speed . feet per min. & $\begin{array}{l}42 \\
31 \\
23\end{array}$ & $\begin{array}{l}56 \\
42 \\
22\end{array}$ & $\begin{array}{l}63 \\
33 \\
19\end{array}$ & $\begin{array}{l}61 \\
44 \\
19\end{array}$ & $\begin{array}{l}65 \\
38 \\
22\end{array}$ \\
\hline Revolutions per min. . & $\begin{array}{r}106 \\
80 \\
58\end{array}$ & $\begin{array}{r}106 \\
80 \\
42\end{array}$ & $\begin{array}{l}80 \\
42 \\
24\end{array}$ & $\begin{array}{l}58 \\
42 \\
18\end{array}$ & $\begin{array}{l}42 \\
24 \\
14\end{array}$ \\
\hline Material removed cu. in. per min. & $\left\{\begin{array}{l}1 \cdot 067 \\
1 \cdot 04 \\
1 \cdot 04\end{array}\right.$ & $\begin{array}{l}1 \cdot 047 \\
1 \cdot 047 \\
0 \cdot 958\end{array}$ & $\begin{array}{l}1 \cdot 037 \\
0.944 \\
0.756\end{array}$ & $\begin{array}{l}0.93 \\
0.81 \\
0.67\end{array}$ & $\begin{array}{l}1 \cdot 051 \\
0 \cdot 771 \\
0 \cdot 507\end{array}$ \\
\hline $\begin{array}{l}\text { Net h.p. absorbed by out only. } \\
\text { Maintained during test . }\end{array}$ & 10 & 10 & 10 & 10 & 10 \\
\hline $\begin{array}{l}\text { Efficiency per cent. for each dia- } \\
\text { meter of shaft. }\end{array}$ & $\begin{array}{r}100 \\
97 \\
97\end{array}$ & $\begin{array}{c}100 \\
100 \\
91 \cdot 5\end{array}$ & $\begin{array}{r}100 \\
91 \\
73\end{array}$ & $\begin{array}{r}100 \\
87 \\
72\end{array}$ & $\begin{array}{l}100 \\
73 \cdot 3 \\
48 \cdot 2\end{array}$ \\
\hline $\begin{array}{l}\text { Efficiency per cent. over the range } \\
\text { of shafts. }\end{array}$ & $\begin{array}{r}100 \\
97 \\
97\end{array}$ & $\begin{array}{l}98 \\
98 \\
89\end{array}$ & $\begin{array}{l}97 \\
88 \\
70\end{array}$ & $\begin{array}{l}87 \\
76 \\
63\end{array}$ & $\begin{array}{l}98 \\
72 \\
47\end{array}$ \\
\hline
\end{tabular}

Mr. Guzst wrote that, with regard to Mr. Asbridge's interesting tests on work-speeds which he had made since the Manchester 
Meeting, some deduction could be made. Owing to the type of feed used, the wheel being fed into the work by hand, individual results might be somewhat out, but the general conclusions would be correct. When the wheel was thus fed, keeping the power constant but neglecting wheel-wear, the rate of removing material would depend upon the state of the wheel, whether it were glazing or wasting, in the following manner. The more it was glazing the less material would be removed, but when the wheel was keeping keen by wear, there would be practically no difference whether it were only just wearing normally or wasting considerably. Thus if the relative efficiency were high-say over 95 per cent. - all that could be deduced was that the wheel was not glazing, but to what extent it was wasting could not be determined. Accordingly, these tests determined the point where glazing began.

The results were summarized in the last lines entitled " efficiency per cent. over the range of shafts." Considering the lowest line first, it was clear that at a work-surface speed of 20 feet per minute, the efficiency fell off regularly as the diameter increased; this applied also to other speeds, and was clearly a general law, for there was no particular virtue in any one speed. At the 20 feet per minute, a 10 per cent. (nearly enough) drop occurred at $1 \frac{1}{2}$ inch diameter, the efficiency falling from 0.97 to 0.89 with the diametrical increase from $1 \frac{1}{2}$ inch to 2 inches. A 10 per cent. drop first occurred in the 40 feet per minute series at 2 inches diameter $(0.98$ to 0.88$)$, and in the 60 feet per minute series at 3 inches diameter $(0 \cdot 97$ to $0 \cdot 87)$, so that these might be taken to be corresponding diameters at the various speeds. If the experimental results were plotted into curves, with the material removed and the work-diameter as ordinates and abscissæ respectively, the shape of the curves would be similar to steamengine diagrams - the admission period corresponding to wheel-wear and waste, and the expansion line to the glazing, the cut-off being the glazing point.

Probably the best speed to run at is just at the glazing point, of which 2-inch diameter work at 40 feet per minute was representative. According to the Author's theory, work of greater 
(Mr. Guest.)

diameter than 2 inches would glaze at 40 feet per minute. As an example, consider the case of 6 -inch work running at this speed. Equation 5 (page 555), inserting the values from the 2-inch diameter experiment, gave

$$
42=\frac{a c}{b} \times \frac{2 \times 26}{2+26}, \text { so that } \frac{a c}{b}=\frac{42 \times 28}{2 \times 26}=23 .
$$

Taking the values for 6 -inch diameter work gave

$$
\frac{a c}{b}=\frac{38 \times(6+26)}{6 \times 26}=8 .
$$

Since $b$ and $c$ were the same in the two cases, $a$ had been reduced to $\frac{8}{23}$ of its previous value, so that the wheel would glaze according to the theory. This was typical of the whole change indicated by theory, which gave such a fall as was indicated by the experiments.

Taking the same experiment-2 inches diameter at 42 feet per minute- - let it be asked at what diameter work moving at 60 feet per minute should be on the glazing point. Substituting in equation 5, it now gave

$$
60=\frac{a c}{b} \times \frac{d \times 26}{(d+26)}
$$

and $\frac{a c}{b}$ has the same value (23) as previously found;

$\therefore(d+26) 60=\frac{42 \times 28}{2 \times 26} \times d \times 26$, or $d=3$ inches nearly.

In the same way it could be found that, at 20 feet per minute, work of 0.9 inch diameter would be at the glazing point. Comparing these calculations with the points previously noted in the experiments at which the 10 per cent. drop first occurred, the correspondence was close enough to strengthen belief considerably in the reliability of the Author's theory.

The experiments established the fact that a work-speed of 40 feet per minute worked perfectly on material of 2 inches diameter, but failed more and more with increase of work-diameter. This constituted a definite proof that the usual assumption, that the work-surface speed should be constant, was incorrect. 